\title{
Light Chain Proximal Tubulopathy without Crystals
}

National Cancer Institute

\section{Source}

National Cancer Institute. Light Chain Proximal Tubulopathy without Crystals. NCI

Thesaurus. Code C158966.

A morphologic variant of light chain proximal tubulopathy with no evidence of crystal

formation. It is characterized by acute tubular injury with no evidence lysosomal

immunog lobulin crystals. 